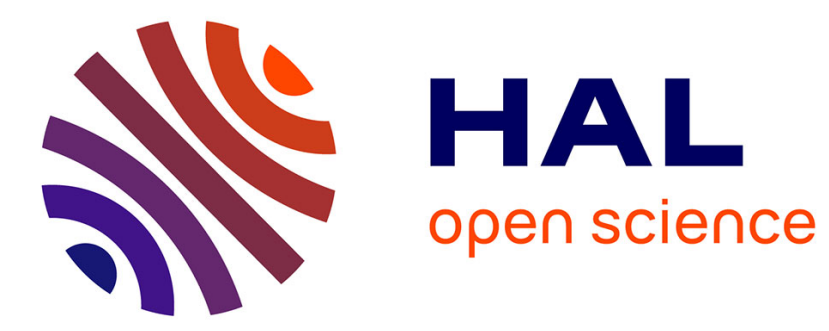

\title{
Nitrolic acids: efficient precursors of nitrile oxides under neutral conditions
}

Christophe Matt, Arnaud Gissot, Alain Wagner, Charles Mioskowski

\section{To cite this version:}

Christophe Matt, Arnaud Gissot, Alain Wagner, Charles Mioskowski. Nitrolic acids: efficient precursors of nitrile oxides under neutral conditions. Tetrahedron Letters, 2000, 41 (8), pp.1191-1194. 10.1016/S0040-4039(99)02278-9 . hal-02492631

\section{HAL Id: hal-02492631 \\ https://hal.science/hal-02492631}

Submitted on 27 Feb 2020

HAL is a multi-disciplinary open access archive for the deposit and dissemination of scientific research documents, whether they are published or not. The documents may come from teaching and research institutions in France or abroad, or from public or private research centers.
L'archive ouverte pluridisciplinaire HAL, est destinée au dépôt et à la diffusion de documents scientifiques de niveau recherche, publiés ou non, émanant des établissements d'enseignement et de recherche français ou étrangers, des laboratoires publics ou privés. 


\title{
Nitrolic acids: efficient precursors of nitrile oxides under neutral conditions
}

\author{
Christophe Matt, Arnaud Gissot, Alain Wagner* and Charles Mioskowski* \\ Laboratoire de Synthèse Bioorganique, Université Louis Pasteur de Strasbourg, UMR 7514 du \\ CNRS, Faculté de Pharmacie, 74 route du Rhin-BP 24-67401 Illkirch, France
}

\begin{abstract}
Nitrolic acids are prepared in good yields from primary nitroalkanes or primary alkyl bromides. Upon heating in THF, they afford the corresponding nitrile oxides under neutral conditions. In the presence of dipolarophiles, isoxazoles are obtained in yields up to $95 \%$. For the less stable alkoxycarbonyl- and aryInitrolic acids the crude nitrolic acids can be directly engaged in the cycloaddition reaction.
\end{abstract}

Keywords: nitrile oxides; alkyl halides; nitro compounds; cycloadditions; nitrolic acids.

Nitrolic acids, obtained by careful addition of dilute acid to a mixture of nitroalkane anion and potassium nitrite, were first reported by Meyer in $1873 .{ }^{1}$ Since then, only scanty reports dealing with their synthesis, stability and use are found in the literature. ${ }^{2}$ We recently reported the transformation of primary nitroalkanes or primary alkyl bromides into carboxylic acids under mild conditions, using a mixture of acetic acid and sodium nitrite in DMSO at $50^{\circ} \mathrm{C}^{3}$ We noticed that, when the reaction is carried out at $20^{\circ} \mathrm{C}$, the nitrolic acid, which is the intermediate of the above transformation, could be isolated in good yield. Nitrolic acids, prior to this work, were known to be highly unstable, difficult to handle and prone to decomposition upon heating via formation of the corresponding nitrile oxides. ${ }^{4}$ For these reasons and presumably because of the lack of a simple and reliable method for their synthesis, thermolytic fragmentation of nitrolic acids has never been considered as a synthetically useful reaction for the generation of nitrile oxides. Herein we demonstrate the synthetic potential of our novel preparative method of nitrolic acids and investigate their use as precursors of nitrile oxides for 1,3-dipolar cycloadditions (Scheme 1).

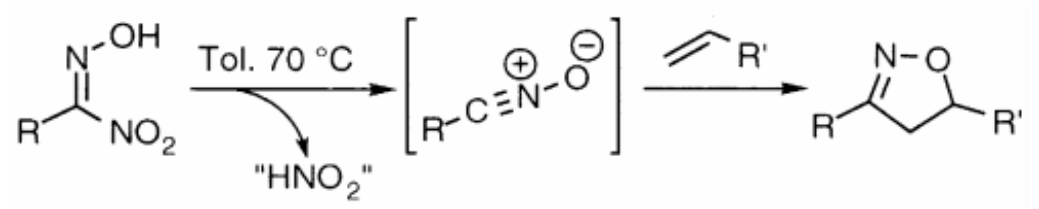

Scheme 1

\footnotetext{
* Corresponding authors. Fax: 333886788 91;

e-mail: alwag@aspirine.u-strasbg.fr (A. Wagner), mioskow@aspirine.u-strasbg.fr (C. Mioskowski)
} 
In a preliminary study, we prepared a series of nitrolic acids from nitro or bromo precursors. Upon treatment with a mixture of acetic acid and sodium nitrite in DMSO, ${ }^{5}$ the conversion of the nitroalkyl substrate is always higher than $80 \%$, according to NMR analysis of the crude. However the stability of the nitrolic acids proved to be dramatically dependent on their substituents. Alkylnitrolic acids can be easily isolated and purified by silica gel chromatography in around $90 \%$ yield and stored for several months at $-20^{\circ} \mathrm{C}$. In contrast, alkoxycarbonyl- or arylnitrolic acids are rather unstable and tend to decompose during column chromatography. Moreover they have a strong tendency to give rise to the corresponding nitrile oxide, as witnessed by the formation of furoxanes after a few days even at $-20^{\circ} \mathrm{C}$. As a consequence, the alkoxycarbonyl- and arylnitrolic acids are isolated in $50 \%$ yield after purification. Conversion of nitrolic acids into nitrile oxides is promoted by gentle heating. To perform the cycloadditions, we simply carried out the reactions by heating THF solutions of nitrolic acids in the presence of dipolarophiles. The results obtained from reactions of purified nitrolic acids and various dipolarophiles are summarized in Table 1.

Table 1

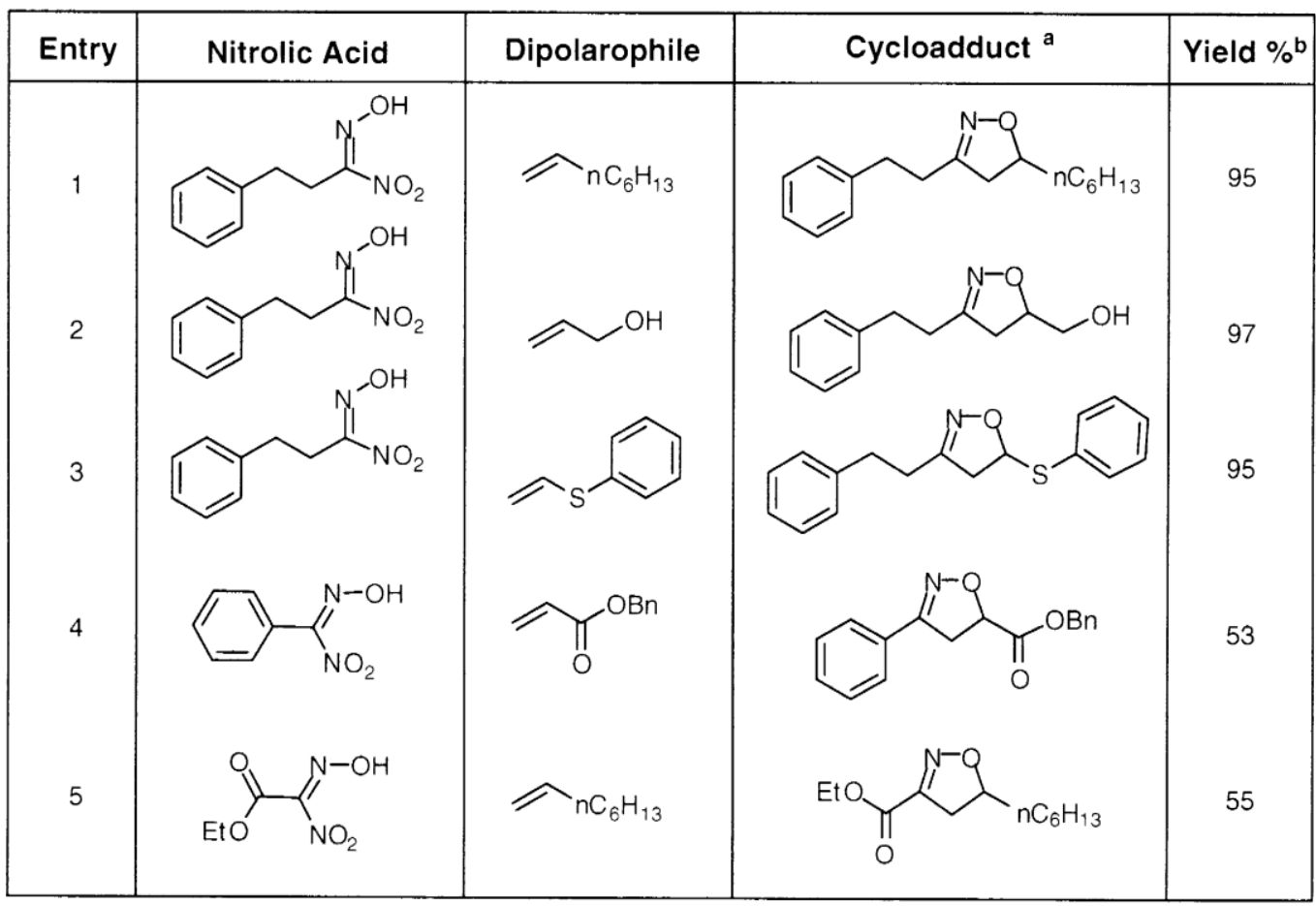

${ }^{\mathrm{a}}$ The cycloadditions were carried out in THF under reflux for 10 hours, at concentration of $0.25 \mathrm{M}$ of nitrolic acids, and $0.75 \mathrm{M}$. of dipolarophile. Identical results are obtained in refluxing toluene ${ }^{\mathrm{b}}$ Isolated yields after purification (calculated from the nitrolic acid).

Thermolysis of alkylnitrolic acids in the presence of alkenes affords cycloadducts in almost pure forms (entry 1). Since the conditions are neutral and do not require strong dehydrants or strong oxidants like classical methods for generation of nitrile oxides, unprotected alcohols (entry 2) and highly oxidizable sulfur moieties (entry 3) are compatible with the reaction conditions. The cycloadducts are obtained in 97 and $95 \%$ yield, respectively. Starting from an arylnitrolic acid, the cycloadduct is obtained in $53 \%$ yield 
(entry 4). This moderate yield is due to the formation of $40 \%$ of furoxane derivative arising from nitrile oxide dimerization. Similarly, reaction of alkoxycarbonylnitrolic acid give a mixture of the desired cycloadduct in $55 \%$ isolated yield (entry 5), and of furoxane in $40 \%$ isolated yield. Classical methods for the preparation of nitrile oxides use large excesses of reagent that lead to the formation of by-products. ${ }^{6}$ Thermolytic generation of nitrile oxides operate under stoichiometric and neutral conditions which avoid these drawbacks. At the end of the reaction no work-up is necessary, the cycloadduct being directly obtained after concentration of the crude mixture. Thus, thermolytic generation of nitrile oxide from nitrolic acid appears to be an efficient reaction, especially in the case of alkyl nitrolic acids and in all cases when neutral conditions are required. However the instability of alkoxycarbonyl and arylnitrolic acids during the purification step restrains somewhat the scope of the methodology. To overcome this drawback, we carried out cycloaddition reactions on crude nitrolic acid mixtures obtained from standard work-up of the reaction of bromo or nitro precursors in a mixture of acetic acid and sodium nitrite in DMSO (Table 2).

Table 2

\begin{tabular}{|c|c|c|c|c|}
\hline Entry & $\begin{array}{c}\text { Nitrolic Acid } \\
\text { Precursor }\end{array}$ & Dipolarophile & Cycloadduct & Yield \% \\
\hline 1 & & & &
\end{tabular}

${ }^{\mathrm{a}}$ Nitrolic acids were prepared according to ref. 5

Starting from ethylnitroacetate, the cycloadduct is obtained in $50 \%$ isolated yield (entry 1 ). The only sideproduct of the reaction is the furoxane formed by dimerization of the nitrile oxide. Since under our reaction conditions (mixture DMSO/AcOH/ $\mathrm{NaNO}_{2}$ ) primary alkyl bromides are converted in situ into their corresponding nitro derivatives, these bromides can directly be used as precursors of nitrile oxides. Starting from ethyl bromoacetate (entries 2 and 3), the cycloadduct is obtained in $45 \%$ overall yield as a result of three consecutive one-pot reactions. This result is especially of interest since classical methods for the generation of alkoxycarbonyl nitrile oxides give low yields. ${ }^{7}$ Moreover, it is noteworthy that nitroacetates are difficult to access, while bromoacetates are readily available.

In conclusion, nitrolic acids are easily prepared by reaction of primary bromo or nitro derivatives with a mixture of acetic acid and sodium nitrite in DMSO. Purification on silica gel affords pure alkylnitrolic acids in high yields. Alkoxycarbonyl- and arylnitrolic acids, which are less stable, partly decompose during chromatographic purification. Thermolytic fragmentation of nitrolic acid in the presence of dipolarophiles 
leads to the corresponding isoxazoles under neutral conditions suitable for sensitive substrates. The less stable alkoxycarbonyl- and arylnitrolic acids can be engaged in cycloaddition reactions as crude mixtures.

\section{Acknowledgements}

We thank the Ministère de la Recherche et de l'Enseignement for financial support of this work through a MRE grant to Christophe Matt and Arnaud Gissot.

\section{References}

1. Meyer, V. Ber. 1873, 6, 1492-1498.

2. Godt, H. C.; Quinn, J. F. J. Am. Chem. Soc. 1956, 78, 1461-1464. Khmel'nitskii, L. I.; Novikov, S. S.; Lebedev, O. V. Izvest. Akad. Nauk. SSSR. 1961, 477-482 (Chem. Abstr. 1961, 55, 2389). Egan, C.; Clery, M.; Hegarty, A. F.; Welch, A. J. J. Chem. Soc., Perkin Trans. 1 1991, 249-256. Makhova, N. N.; Ovchinikov, I. V.; Dubonos, V. G.; Strelenko, Y. A.; Khmel'nitsii, L. I. J. Chem. Soc. Mendeleev Commun. 1992, 91-92. Chang, K. R.; Kim, K. Tetrahedron Lett. 1996, 37, 7791-7794.

3. Matt, C.; Wagner, A.; Mioskowski, C. J. Org. Chem. 1997, 62, 234-235.

4. Wieland, H.; Semper, L. Ber. 1906, 39, 2522-2526. Grundmann, C.; Grünanger, P. The Nitrile Oxides; Springer: New York, 1971; pp. 51-52.

5. Preparation of nitrolic acids: Primary nitroalkanes or primary alkyl bromides $(1 \mathrm{mmol})$ were reacted in DMSO $(2 \mathrm{~mL})$ in the presence of acetic acid $(10 \mathrm{mmol})$ and sodium nitrite $(3 \mathrm{mmol})$ at room temperature. After about one hour, ether $(25 \mathrm{~mL})$ was added to the reaction mixture and the organic layer washed successively with a $10 \%$ hydrochloric acid aqueous solution and a sodium bicarbonate saturated solution. The organic layer was then dried over magnesium sulfate and concentrated under vacuum. The crude mixture that usually displayed over $80 \%$ purity in nitrolic acid could be purified by silica gel chromatography or directly involved in the cycloaddition step.

6. Grundmann, C.; Richter, R. J. Org. Chem. 1968, 53, 476-478. Moriya, O.; Takenaka, H.; Iyoda, M.; Urata, Y.; Endo, T. J. Chem. Soc., Perkin Trans. 1 1994, 413-416. Mukaiyama, T.; Hoshino, T. J. Am. Chem. Soc. 1960, 82, 5339-5342. Bachman, G. B.; Strom, L. E. J. Org. Chem. 1963, 28, 1150-1152. McKillop, A.; Kobylecki, R. J. Tetrahedron 1974, 30, 1365-1371. Harada, K.; Kaji, E.; Zen, S. Chem. Pharm. Bull. 1980, 28, 3296-3303. Shimizu, T.; Hayashi, Y.; Teramura, K. Bull. Chem. Soc. Jpn. 1984, 57, 2531-2534. Shimizu, T.; Hayashi, Y.; Shibafushi, H.; Teramura, K. Bull. Chem. Soc. Jpn. 1986, 59, 2827-2831. Maugein, N.; Wagner, A.; Mioskowski, C. Tetrahedron Lett. 1997, 38, 1547-1550.

7. Leslie-Smith, M. G.; Paton, R. M.; Webb, N. Tetrahedron Lett. 1994, 35, 9251-9254. Shimizu, T.; Hayashi, Y.; Teramura, K. Bull. Chem. Soc. Jpn. 1984, 57, 2531-2534. Harada, H.; Kaji, E.; Zen, S. Chem. Pharm. Bull. 1980, 28, 3296-3303. 